\title{
Optimisation of Accelerated Solvent Extraction of Antioxidant Compounds from Rosemary (Rosmarinus officinalis L.), Marjoram (Origanum majorana L.) and Oregano (Origanum vulgare L.) Using Response Surface Methodology
}

\author{
M. Hossain \\ Technological University Dublin \\ Catherine Barry-Ryan \\ Technological University Dublin, Catherine.Barryryan@tudublin.ie \\ Ana Belen Martin-Diana \\ Technological University Dublin, anabelen.martindiana@tudublin.ie \\ Follow this and additional works at: https://arrow.tudublin.ie/schfsehart

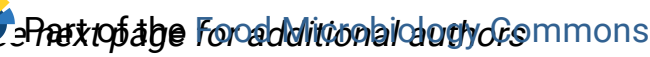

\begin{abstract}
Recommended Citation
Hossain, M., Barry-Ryan, C., Martin-Diana, A., Brunton, N. (2011). Optimisation of accelerated solvent extraction of antioxidant compounds from rosemary (Rosmarinus officinalis L.), marjoram (Origanum majorana L.) and oregano (Origanum vulgare L.) using response surface methodology. Food Chemistry, 126, (1),pp. 339-346. doi:10.1016/j.foodchem.2010.10.076
\end{abstract}

This Article is brought to you for free and open access by the School of Food Science and Environmental Health at ARROW@TU Dublin. It has been accepted for inclusion in Articles by an authorized administrator of ARROW@TU Dublin. For more information, please contact arrow.admin@tudublin.ie, aisling.coyne@tudublin.ie, gerard.connolly@tudublin.ie.

Funder: Irish Department of Agricultur eFisheries and

Food funded Food Institutional Research Measure and ABBEST scholaship programme of Technological University Dublin, Dublin, Ireland

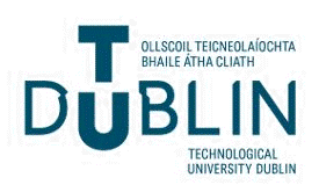




\section{Authors}

M. Hossain, Catherine Barry-Ryan, Ana Belen Martin-Diana, and N. Brunton

This article is available at ARROW@TU Dublin: https://arrow.tudublin.ie/schfsehart/77 


\title{
Optimisation of accelerated solvent extraction of antioxidant compounds from rosemary (Rosmarinus officinalis L.), marjoram (Origanum majorana L.) and oregano (Origanum vulgare L.) using response surface methodology
}

\author{
Food Chemistry 126, p339-346.
}

\author{
M.B. Hossain a,b, Catherine Barry-Ryan a, A.B. Martin-Diana a, N.P. Brunton b \\ aSchool of Food Science and Environmental Health, Dublin Institute of Technology, Dublin, Ireland \\ bTeagasc, Ashtown Food Research Centre, Ashtown, Dublin 15, Ireland
}

\begin{abstract}
The present study optimised the accelerated solvent extraction (ASE) conditions (Dionex ASEÒ 200, USA) to maximise the antioxidant capacity of the extracts from three spices of Lamiaceae family; rosemary, oregano and marjoram. Optimised conditions with regard to extraction temperature $\left(66-129^{\circ} \mathrm{C}\right)$ and solvent concentration (32-88\% methanol) were identified using response surface methodology (RSM). For all three spices results showed that $129^{\circ} \mathrm{C}$ was the optimum temperature in order to obtain extracts with high antioxidant activity. Optimal methanol concentrations with respect to the antioxidant activity of rosemary and marjoram extracts were $56 \%$ and $57 \%$ respectively. Oregano showed a different response to the effect of methanol concentration and was optimally extracted at $33 \%$. The antioxidant activity yields of the optimal ASE extracts were significantly $(p<0.05)$ higher than solid/liquid extracts. The predicted models were highly significant $(p<0.05)$ for both total phenol (TP) and ferric reducing antioxidant property (FRAP) values in all the spices with high regression coefficients (R2) ranging from 0.952 to 0.999 .
\end{abstract}

Keywords: Antioxidant, Spice, Accelerated solvent extraction, Total phenols \& RSM

1. Introduction

Numerous studies have demonstrated that spices have potent antioxidant properties, mostly due to the quantity and quality of polyphenolic compounds present in them (Hossain, Brunton, Barry-Ryan, Martin-Diana, \& Wilkinson, 2008; Shan, Cai, Sun, \& Corke, 2005). This has led to the use of extracts from spices in many food applications (Hirasa \& Takemasa, 1998). To date a large number of studies have focused on rosemary (Rosmarinus officinalis L.) due to the high antioxidant capacity of this spice (Shan et al., 2005). In fact this property has led to the use of rosemary as a food preservative, either in ground form or as an extract (Peng, Yuan, Liu, $\&$ Ye, 2005). Several studies reported that methanolic extracts of marjoram (Origanum majorana L.) had high antioxidant capacity (Hossain et al., 2008; Zheng \& Wang, 2001). Marjoram is traditionally administered, orally, for symptomatic treatment of gastrointestinal disturbances and cough. Its spasmolytic and antimicrobial effects are used to treat bronchial diseases. Marjoram is also applied topically to relieve symptoms of the common cold, such as nasal congestion and in mouthwashes for oral hygiene (Bruneton,

1999). Oregano (Origanum vulgare L.) is used as a medicinal plant with health imparting properties such as powerful anti-bacterial and anti-fungical properties (Elgayyar, Draughon, Golden, \& Mount, 2001). The compounds for these biological properties are polyphenolic secondary metabolites such as rosmarinic acid, carvacrol, caffeic acid, thymol (Zheng \& Wang, 2001). These compounds have been shown to have anticarcinogenic, antimicrobial, antiviral, hypolipidemic, antimutagenic, anti-inflammatory and anticardiovascular disease properties (Lampe, 2003; Srinivasan, 2005). This diverse range of biological properties makes spice phenolics an interesting target for optimising their extraction condition from a natural source. Traditionally extraction of these compounds has been carried out using conventional solid/liquid extraction at atmospheric pressures (Suhaj, 2006). The extraction of phenolic compounds from spices is dependent on several factors such as the extraction medium, temperature, time, pressure, particle size and solvent to herb/spice ratio (Juntachote, Berghofer, Siebenhandl, \& Bauer, 2006). Accelerated solvent extraction is relatively a new automated technique which uses low-boiling solvents or solvent mixtures at elevated temperatures up to $200^{\circ} \mathrm{C}$ and pressure (3000 psi) to extract target compounds. This increases target compound solubility, solvent diffusion rate and mass transfer, while solvent viscosity and surface tension decrease. ASE presents many advantages over traditional solid/liquid extraction techniques. For example, solid/ liquid extraction methods use large quantities of toxic organic solvents, are labour intense, require long extraction times, possess low selectivity and/or low extraction yields, and can result in the 
expose of extracts to excessive heat, light and oxygen. In contrast, ASE uses less solvent in a shorter period of time, is automated and retains samples in an oxygen- and light-free environment (Denery,

Dragull, Tang, \& Li, 2004). Several authors (Babovic et al., 2010; Simándi et al., 1998; Zizovic, Stamenic, Orlovic, \& Skala, 2005) proposed supercritical carbon dioxide extraction as a quick and green alternative to conventional solid/liquid extraction. However, its use has been limited due to its low efficiency to extract polar compounds. A considerable number of studies have focussed on the use of ASE from an environmental perspective (Okuda, Yamashita, Tanaka, Matsukawa, \& Tanabe, 2009; Siriwong et al., 2009). Some studies have reported the use of ASE to extract specified target compounds from spices (Herrero et al., 2005; Zaibunnisa, Norashikin, Mamot, \& Osman, 2009). However, none have concentrated on maximising the antioxidant capacity of spice extracts. To maximise antioxidant capacity of the extracts, ASE extraction conditions (temperature, solvent composition and pressure) must be optimised. Response surface methodology (RSM) is a statistical technique which allows the user to identify optimal conditions for a selected response while minimising the number of experiments required. RSM was first introduced by Box and Wilson (1951) and it generally requires fewer experimental runs than that required for full factorial designs, while providing statistically acceptable results (Tan, Ghazali, Kuntom, Tan, \& Ariffin, 2009). Central composite design (CCD) is the most popular form of RSM as it has been utilised by a number of researchers to optimise various food processing methods such as milling (Ghodke, Ananthanarayan, \& Rodrigues, 2009), extraction (Huang, Li, Niu, Li, \& Zhang, 2008; Lee, Yusof, Hamid, \& Baharin, 2006) and fermentation (Dhandhukia \& Thakkar, 2008). In the present study, optimisation of solvent concentration and temperature for extracting antioxidant compounds from spices was carried out using accelerated solvent extraction (ASE) in conjunction with response surface methodology.

Table 1 of methanol concentration and temperature obtained from RSM.

$\begin{array}{rlr}\text { Run } & \text { Methanol\% } & \text { Temperature }\left({ }^{\circ} \mathrm{C}\right) \\ 1 & 60 & 97 \\ 2 & 40 & 120 \\ 3 & 60 & 97 \\ 4 & 32 & 97 \\ 5 & 40 & 75 \\ 6 & 60 & 66 \\ 7 & 80 & 120 \\ 8 & 88 & 97 \\ 9 & 80 & 75 \\ 10 & 60 & 97 \\ 11 & 60 & 129 \\ 12 & 60 & 97 \\ 13 & 60 & 97\end{array}$

pressurised (1500 psi), and then heated for 5 min followed by a static period of $5 \mathrm{~min}$. The sample was extracted with the specified methanol concentration and temperature during this $5 \mathrm{~min}$. Then, the cell was rinsed with fresh extraction solvent $(60 \%$ of the extraction cell volume) and purged with a flow of nitrogen (150 psi during $90 \mathrm{~s}$ ). Extracts (34 mL) were collected into $60 \mathrm{~mL}$ glass vials. The solvent used was previously degassed with nitrogen to avoid the oxidation of the analytes under the operating conditions. The extracts were stored at $\hat{\mathrm{A}} 20^{\circ} \mathrm{C}$ in darkness until analysis. Then, the extract was filtered through a $0.45 \mathrm{~lm}$ PTFE filters (Millipore, USA) before antioxidant activity and HPLC analyses. The experiment was performed in two batches which included three replications in each sample.

\subsection{Preparation of solid/liquid extracts}

\section{Materials and methods}

\subsection{Samples and reagents}

The spices were provided by AllinAll Ingredients Limited, Dublin 12 as dry and ground form. The country of origin of the spices was Turkey. The plants were grown in sunny and well drained land with annual rainfall of around 15 in. As per the product specifications the samples were air dried at ambient temperature $\left(\$ 23^{\circ} \mathrm{C}\right.$ ) after heat treatment (steam sterilization at $120^{\circ} \mathrm{C}$ for $30 \mathrm{~s}$ ). Folin-Ciocalteu Reagent, gallic acid, sodium acetate anhydrous, ferric chloride hexahydrate, 2,4,6-tri(2-pyridyl)-s-triazine, 6-Hydroxy-2,5,7,8-tetramethylchroman-2-carboxylic acid, sodium carbonate, rosmarinic acid were purchased from Sigma-Aldrich.

\subsection{Accelerated solvent extraction (ASE) procedure}

ASE was performed on a Dionex ASE 200 (Dionex Corp., Sunnyvale, CA) system. Dried and powdered spices $(0.5 \mathrm{~g})$ were placed in between two layers of diatomaceous earth in a $22 \mathrm{~mL}$ Dionex (ASE 200) stainless-steel cell. The cells were equipped with a stainless steel frit and a cellulose filter (Dionex Corp.) at the bottom to avoid the collection of suspended particles in the collection vial. A dispersing agent (diatomaceous earth), was used to reduce the solvent volume used for the extraction. The extraction cell was arranged in the cell tray and was extracted using conditions obtained from RSM guided experimental design. The combinations of solvent concentrations and temperatures used in ASE system are presented in Table 1.

The auotomated extraction cycle was as follows: the cell containing the sample was prefilled with the extraction solvent,
Dried and ground samples $(0.5 \mathrm{~g})$ were homogenised for $1 \mathrm{~min}$ at 24,000 rpm using an Ultra-Turrax T-25 Tissue homogenizer (Janke \& Kunkel, IKAò-Labortechnik, Saufen, Germany) in $25 \mathrm{~mL}$ of $80 \%$ methanol at room temperature $\left(\$ 23^{\circ} \mathrm{C}\right)$. The homogenised sample suspension was shaken overnight with a V400 Multitude Vortexer (Alpha laboratories, North York, Canada) at 1500 rpm in room temperature. The sample suspension was then centrifuged for $15 \mathrm{~min}$ at 2000g (MSE Mistral 3000i, Sanyo Gallenkamp, Leicestershire, UK) and filtered through $0.22 \mathrm{~lm}$ polytetrafluoethylene (PTFE) filters. The extract was kept at $\mathrm{A} 20^{\circ} \mathrm{C}$ until subsequent analysis.

\subsection{Determination of total phenolic content}

The total phenolic content was determined using Folin-Ciocalteu Reagent (FCR) as described by Singelton, Orthofer, and LamuelaRaventos (1999). The experiment was performed in two batches which included three replications in each for both samples and standard. Methanolic gallic acid solutions (10-400 mg/L) were used as standards. In each replicate, $100 \mathrm{lL}$ of the appropriately diluted sample extract, $100 \mathrm{lL}$ methanol, $100 \mathrm{lL}$ FCR and finally $700 \mathrm{lL} \mathrm{Na} \mathrm{CO}_{3}$ (20\%) were added together and vortexed. The mixture was incubated for $20 \mathrm{~min}$ in the dark and room temperature. After incubation the mixture was centrifuged at 13,000 rpm for $3 \mathrm{~min}$. The absorbance of the supernatant was measured at $735 \mathrm{~nm}$ by spectrophotometer. The total phenolic content was expressed as gallic acid equivalent (GAE)/100 g dry weight (DW) of the sample.

\subsection{Ferric ion reducing antioxidant power (FRAP) assay}

The FRAP assay was carried out as described by Stratil, Klejdus, and Kuban (2006) with slight modifications. The FRAP reagent was 
prepared by mixing $38 \mathrm{mM}$ sodium acetate anhydrous in distilled water $\mathrm{pH}$ 3.6, $20 \mathrm{mM} \mathrm{FeCl}_{3} \mathrm{Á}_{6} \mathrm{H}_{2} \mathrm{O}$ in distilled water and $10 \mathrm{mM}$ 2,4,6-tri(2-pyridyl)-s-triazine (TPTZ) in $40 \mathrm{mM} \mathrm{HCl}$ in a proportion of 10:1:1. This reagent was freshly prepared before each experiment. To each sample $100 \mathrm{lL}$ of appropriately diluted sample extract and $900 \mathrm{lL}$ of FRAP reagent was added and the mixture was incubated at $37^{\circ} \mathrm{C}$ for 40 min in the dark. In the case of the blank $100 \mathrm{lL}$ of methanol was added to $900 \mathrm{lL}$ of FRAP reagent. The absorbance of the resulting solution was measured at $593 \mathrm{~nm}$ by spectrophotometer. Trolox (6-hydroxy-2,5,7,8-tetramethylchroman-2-carboxylic acid) (a synthetic antioxidant) at concentrations from $0.1 \mathrm{mM}-0.4 \mathrm{mM}$ was used as a reference antioxidant standard. FRAP values were expressed as $\mathrm{g}$ Trolox/100 $\mathrm{g}$ DW of the sample.

\subsection{Determination of melanoidins}

To estimate the degree of formation of browning compounds such as melanoidins the absorbance at $420 \mathrm{~nm}$ was measured, this wavelength has previously been used to detect browning defects in fruit juices (Ibarz, Pagán, Panadés, \& Garza, 2005). The extracts were diluted four times before measuring the absorbance as some of the extracts had very high absorbance (>2.50).

\subsection{HPLC analysis of the extracts}

High performance liquid chromatography (HPLC) of the filtered sample extracts were carried out according to the method of Tsao and Yang (2003). The chromatographic system (Shimadzu-Model no SPD-M10A VP, Mason Technology, Dublin 8, Ireland) consisted of a pump, a vacuum degasser, a Diode-Array Detector and was controlled through EZ Start 7.3 software (Shimadzu) at $37^{\circ} \mathrm{C}$. An Agilent C18 column (15 cm Â $4.6 \mathrm{~cm}, 5 \mathrm{~lm}$, Agilent Technologies., USA) was utilised with a binary mobile phase of $6 \%$ acetic acid in $2 \mathrm{mM}$ sodium acetate (final $\mathrm{pH} 2.55$, v/v, solvent $A$ ) and acetonitrile (solvent $B$ ). Solvent A was prepared first by making $2 \mathrm{mM}$ sodium acetate water solution, which was then mixed with acetic acid at a ratio of $94: 6$ by volume. All solvents were filtered through a $0.45 \mathrm{~lm}$ membrane filter prior to analysis. The flow rate was kept constant at $1.0 \mathrm{~mL} / \mathrm{min}$ for a total run time of $80 \mathrm{~min}$. The following gradient programme was carried out: $0-15 \% \mathrm{~B}$ in $45 \mathrm{~min}$ $15-30 \%$ B in 15 min, 30-50\% B in 5 min, 50-100\% B in 5 min and $100-0 \%$ B in $10 \mathrm{~min}$. The injection volume for all the samples was $10 \mathrm{lL}$. All the standards for quantification purposes were dissolved in methanol. The data acquired at 280, 320, 360 and $520 \mathrm{~nm}$ were used for simultaneous monitoring of different groups of polyphenols. Identification of compounds was achieved by comparing their retention times and UV-Vis spectra with those of authenticated standards in the library that was built by using the inline DAD with a 3D feature. As recommended by Tsao and Yang (2003) hydroxybenzoic acid derivatives, flavan-3-ols (including their dimers) and dihydrochalcones were quantified at $280 \mathrm{~nm}$; hydroxycinnamic acid derivatives at $320 \mathrm{~nm}$; flavanols at $360 \mathrm{~nm}$ and anthocyanins at $520 \mathrm{~nm}$.

\subsection{Statistical analysis}

Optimal ASE extraction conditions were determined by RSM which was performed using the Design Expert Version 7.1.3 software (Stat-Ease, Inc., Minneapolis, MN). A central composite design (CCD) was used to investigate the effects of two independent variables (solvent concentration and extraction temperature) on the dependent variables (TP and FRAP). The data obtained from the CCD design was fitted with a second order polynomial equation. The equation was as follows:

$$
Y=\beta_{0}+\sum_{i=1}^{2} \beta_{i} X_{i}+\sum_{i=1}^{2} \beta_{i=1} X_{i}^{2}+\sum_{i} \sum_{j=1+1} \beta_{i} X_{i} X_{j}
$$

where $Y$ is the predicted response; $b_{0}$ is a constant; $b_{i}$ is the linear coefficient; $b_{i i}$ is the quadratic coefficient, $b_{i j}$ is the interaction coefficient; and $X_{i}$ and $X_{j}$ are independent variables. The adequacy of the model was determined by evaluating the lack of fit, coefficient of regression $\left(R_{2}\right)$ and the Fisher test value (F-value) obtained from the analysis of variance (ANOVA). Statistical significance of the model and model variables was determined at the $5 \%$ probability level $(p<0.05)$. The software uses the quadratic model equation shown above to build response surfaces. Three-dimensional response surface plots were generated by keeping one response variable at its optimal level and plotting that against two factors (independent variables). The complete design consisted of 13 experimental points including five replications of the central point. The actual values of the factors for the experimental designs are given in Table 1.

3. Results and discussion

3.1. Optimisation of extraction condition from rosemary, marjoram and oregano

Fig. 1 presents response surface plots showing the effect of methanol concentration and temperature on TP and FRAP values of rosemary, marjoram and oregano. Using ASE (Dionex ASEò 200 , USA), the optimal temperature for obtaining extracts with high antioxidant capacity was $129^{\circ} \mathrm{C}$ in all the spices tested. In fact temperature was found to be the dominant factor in maximising the phenolic content and antioxidant capacity as measured by FRAP values of the extracts. This result was in agreement with the findings of Zgórka (2009) who reported that concentrations of isoflavone obtained from Clover (Trifolium L.) using ASE increased with increasing temperature from $75^{\circ} \mathrm{C}$ to $125^{\circ} \mathrm{C}$ with no evidence of thermal degradation of the target compounds. Several other studies using ASE also reported the similar effect of temperature on extraction yield of phenolics from plant materials (Santoyo et al., 2009; Zaibunnisa et al., 2009). This is not surprising since increasing temperatures enhances the solubility of many compounds. High temperatures might also have increased the diffusion rate of the compounds resulting in antioxidant compounds being extracted at a higher rate. Interestingly ASE offers a unique possibility of using high temperature at very high pressure (1500 psi) while preventing degradation of the extracted compounds. This is because high pressure generally increases the stability of covalent bonds within molecules. In the present study, evidence of thermal degradation could only be detected at temperatures above $150^{\circ} \mathrm{C}$.

For rosemary total phenolic content and FRAP values of the ASE extracts increased with the increasing temperature. A methanol concentration of $50-60 \%$ was optimal with regard to antioxidant activity and total phenolic content of extracts from rosemary. Thus RSM guided optimisation demonstrated that optimum ASE extraction conditions for rosemary were $56 \%$ methanol coupled with a temperature of $129^{\circ} \mathrm{C}$ (Fig. $1 \mathrm{a}$ and $\mathrm{b}$ and Table 2). Similar results were reported by Akowuah, Ismail, Norhayati, and Sadikun (2005) using conventional solid/liquid extraction. They found $50 \%$ aqueous methanol extract of Orthosiphon stamineus showed higher antioxidant capacity and rosmarinic acid content than other methanol concentrations ( $0 \%$ and $100 \%)$ tested. Both temperature and methanol concentration significantly affected the total phenol and FRAP values of the extracts at linear and quadratic levels (Fig. 2a and b). A significant interaction between temperature and methanol concentration was also observed. Optimally extracted ASE rosemary extracts showed significantly $(p<0.05)$ 

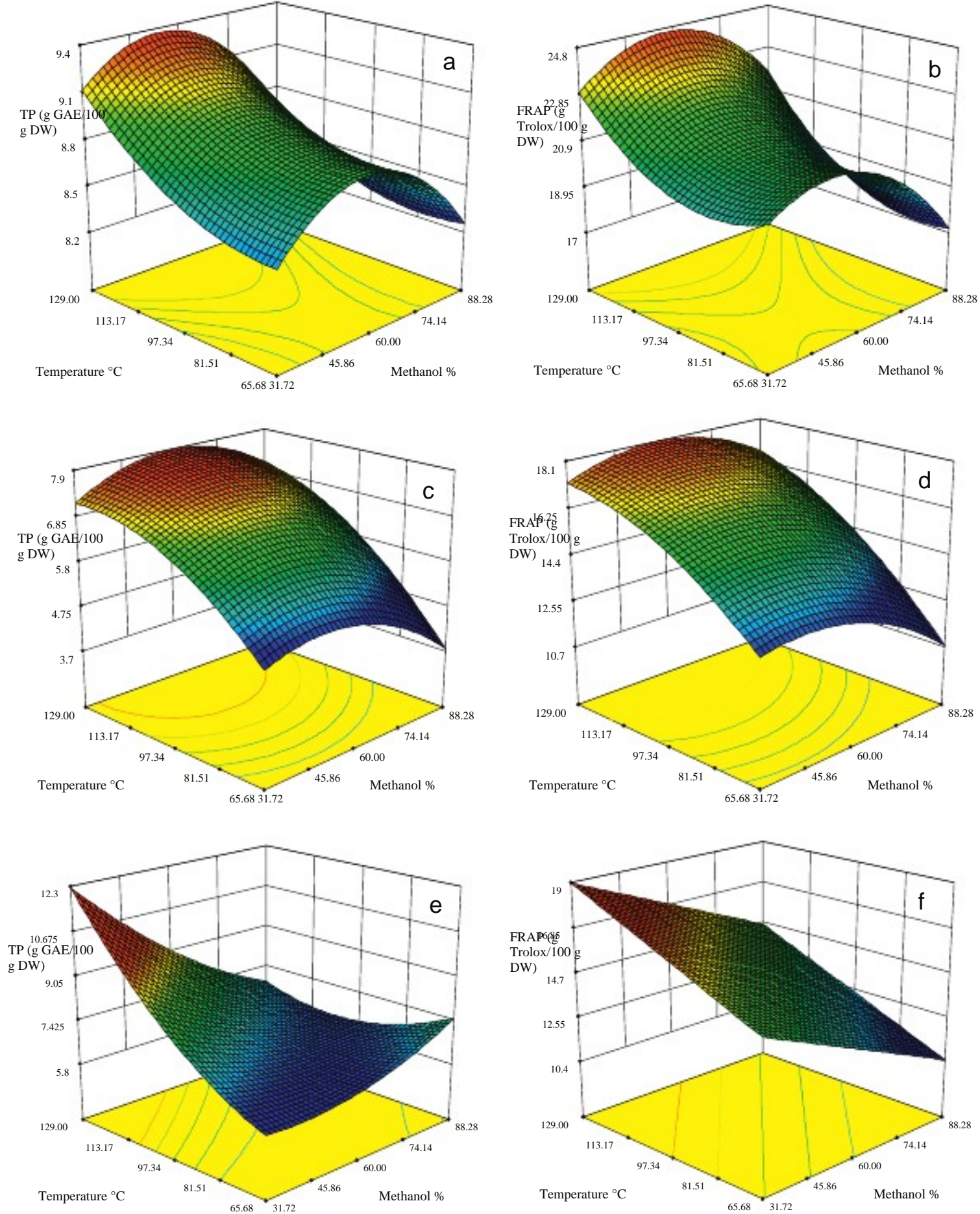

Fig. 1. Response surface plots of rosemary ( $a$ and b), marjoram ( $c$ and $d$ ) and oregano (e and f) showing the effect of methanol concentration and temperature on TP and FRAP values.

higher TP and FRAP values than the conventional solid/liquid extracts (Table 2). In fact the antioxidant capacity as measured by FRAP was $77.52 \%$ higher in the optimal ASE extracts as compared to solid/liquid extracts.

The regression coefficients of both the parameters were high (0.999 for TP and 0.997 for FRAP) and lack of fit statistic was not significant $(p>0.05)$. These results along with high F-values

(1842.13 for TP and 448.10 for FRAP) indicate that the models for TP and FRAP values were significant $(p<0.0001)$ and adequate. The models could efficiently be used for prediction of the TP and
FRAP values as the predicted data correlated highly with experimental data. The Pearson's correlation coefficients of 0.999 for TP and 0.998 for FRAP values reflected the strength of correlation.

Marjoram exhibited similar behaviour to rosemary having an optimal extraction condition of $57 \%$ methanol and $129^{\circ} \mathrm{C}$ (Fig. 1c and $d$ and Table 2). A significant $(p<0.05)$ effect of temperature and methanol concentration was observed on TP and FRAP output variables at both linear and quadratic level. Temperature in general had greater effect than methanol concentration on both the parameters tested (Fig. 2c and d). The interaction was only 
Table 2

Second order polynomial equations and regression coeflicients of the response variables and comparison of antioxidart capacity (AC) at opfimised ASE conditions (ASEC) vs. conventional solid/liquid extracts (SLI).

\begin{tabular}{|c|c|c|c|c|c|c|}
\hline $\begin{array}{l}\text { Spice } \\
\text { name }\end{array}$ & Response variable & Secand order palynamial equation & $R^{2}$ & $\begin{array}{l}\text { Optimum ASEC }(\mathscr{X} \\
\left.\text { methanol/ }{ }^{\circ} \mathrm{C}\right)\end{array}$ & $\begin{array}{l}\text { AC at } \\
\text { optimum } \\
\text { ASEC }\end{array}$ & $\begin{array}{l}\text { AC at } \\
\text { SLE. }\end{array}$ \\
\hline \multirow[t]{2}{*}{ Rosemary } & $\mathrm{TP}(\mathrm{g}$ CAE$/ 100 \mathrm{~g} \mathrm{DW})$ & $\begin{array}{l}Y=7.55433+0.0683756 X_{1}-0.0195193 X_{2}-0.0000722222 X_{1} X_{2} \\
-0.000558124 X_{1}^{2}+0.000166418 X_{2}^{2}\end{array}$ & 0.999 & $56 / 129$ & 10.17 & 858 \\
\hline & FRAP ( $\mathrm{g}$ Tral $\alpha / 100 \mathrm{~g}$ DW) & $\begin{array}{l}Y=26.3383+0.236027 X_{1}-0.286007 X_{2}+0.000555556 X_{1} X_{2} \\
-0.00273437 X_{1}^{2}+0.00159258 X_{2}^{2}\end{array}$ & 0.997 & & 2535 & 1428 \\
\hline \multirow[t]{2}{*}{ Marjaram } & $\mathrm{TP}(\mathrm{g}$ CAE $/ 100 \mathrm{~g} \mathrm{DW})$ & $Y=-5.77246+0.104757 X_{1}+0.163076 X_{2}-0.000966246 X_{1}^{2}$ & 0.965 & $57 / 129$ & 845 & 7.35 \\
\hline & FRAP ( $\mathrm{g}$ Tral $\alpha / 100 \mathrm{~g}$ DW) & $\begin{array}{l}Y=0.674729+0.0841329 X_{1}+0.2081 X_{2}+0.000536076 X_{1} X_{2} \\
-0.001355 X_{1}^{2}-0.000827711 X_{2}^{2}\end{array}$ & 0994 & & 1856 & 1226 \\
\hline \multirow[t]{2}{*}{ Oregano } & $\mathrm{TP}(\mathrm{g}$ CAE $/ 100 \mathrm{~g} \mathrm{DW})$ & $\begin{array}{l}Y=351613+0.0719425 X_{1}-0.00245432 X_{2}-0.00197222 X_{1} X_{2} \\
+0.000719533 X_{1}^{2}+0.000847524 X_{2}^{2}\end{array}$ & 0.998 & $33 / 129$ & 11.75 & 893 \\
\hline & FRAP ( $\mathrm{g}$ Tral $\alpha / 100 \mathrm{~g}$ DW) & $Y=12.8647-0.0761207 X_{1}+0.0660378 X_{2}$ & 0.952 & & 1925 & 1786 \\
\hline
\end{tabular}
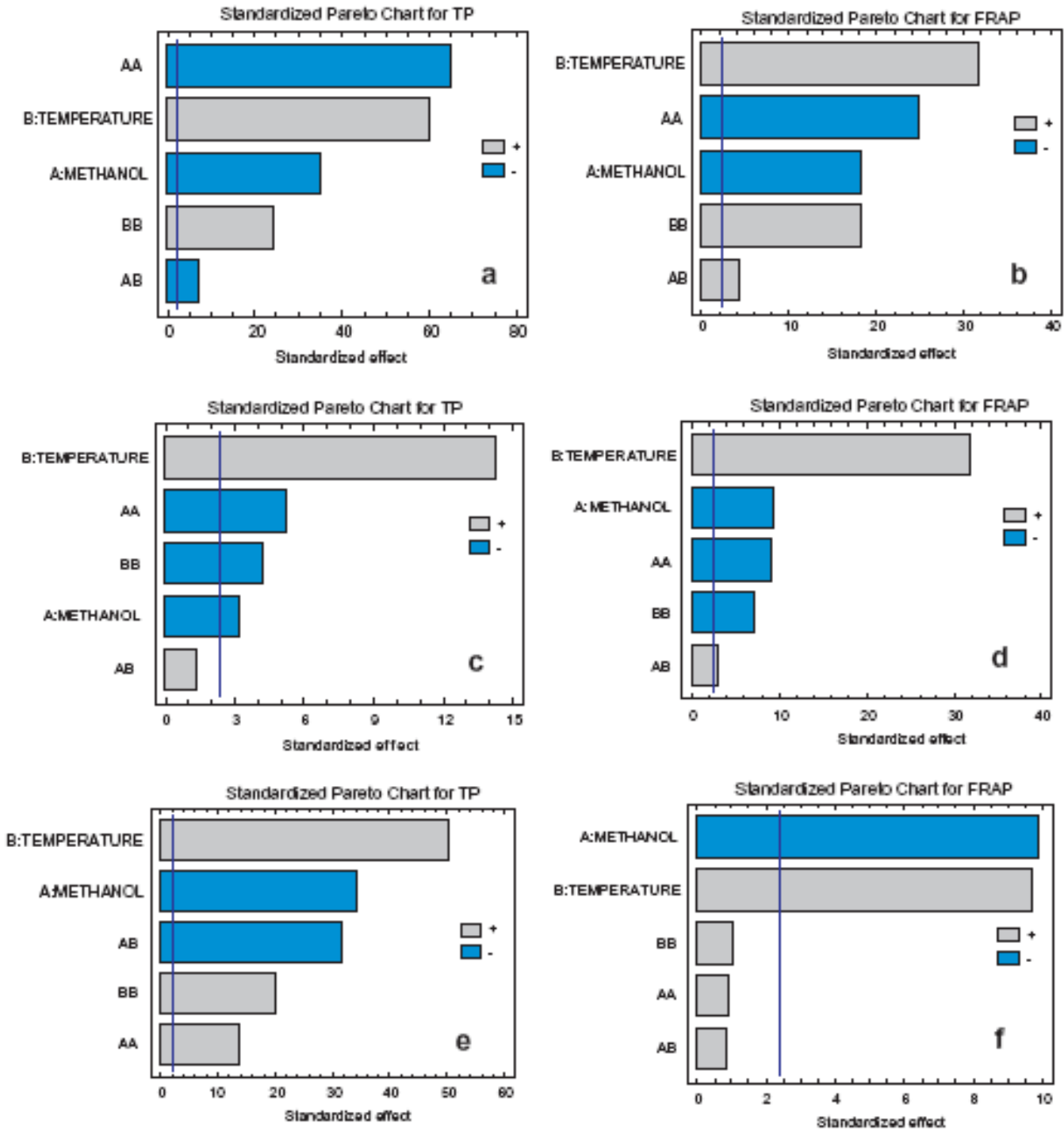

Fig. 2. Standardised pareto chart of rosemary ( $a$ and b), marjoram ( $c$ and $d$ ) and oregano ( $e$ and $f$ ) showing the effect of different factor terms on TP and FRAP values Bars exceeding the vertical line on the graph indicate that the corresponding factor terms are sigrificarnt $(p<005)$. 
significant $(\mathrm{p}<0.05)$ on FRAP values. Total phenol content and FRAP values of optimal marjoram ASE extract were $14.96 \%$ and $51.38 \%$ respectively higher than the solid/liquid extracts. The models were found to be very significant $(p<0.001)$ with respect to ANOVA with high regression coefficients $\left(R_{2}\right)$ of 0.965 for TP and 0.994 for FRAP values (Table 2 ). The data obtained from the assays fitted well with the models as the lack of fit statistic was non-significant $(p>0.05)$. The predicted TP and FRAP values from the models were highly correlated (Pearson's correlation coefficient $=0.986$ for TP and 0.997 for FRAP) with the actual experimental values.

Oregano showed its optimum ASE extraction condition at 33\% methanol and $129^{\circ} \mathrm{C}$ (Fig. 1e and $\mathrm{f}$ and Table 2). This may indicate that oregano contains more hydrophilic antioxidant compounds than the other two spices examined. It is well known that solvent polarity can significantly affect the extraction yield depending on the polarity of the target analyte (Zgórka, 2009).

Pareto chart analysis showed that temperature and methano concentration significantly affected the total phenolic content at both linear and quadratic level. Interaction effect was also significant for TP values. The FRAP values were affected at a linear level by both the factors. The effect of temperature was positive whereas the effect of methanol concentration was negative (Fig. $2 e$ and $f$ ).

The models for TP and FRAP in oregano were significant $(p<0.0001)$ and highly predictive. The regression coefficients for TP and FRAP values were 0.998 and 0.952 respectively (Table 2 ) and the lack of fit was non-significant $(p>0.05)$. The predicted TP and FRAP values from models showed high correlation (Pearson's correlation coefficient, $r=0.999$ for TP and 0.975 for FRAP) with the actual values. perature of the optimal extraction condition was increased from $129^{\circ} \mathrm{C}$ to $200^{\circ} \mathrm{C}$, a sharp decrease of rosmarinic acid in the extracts was observed (Fig. 3 and Table 3). However, total phenolic content and FRAP values continued to increase at these temperatures. This could be explained by degradation of rosmarinic acid into compound/s which had higher antioxidant activity than rosmarinic acid. Moreover loss of rosmarinic acid occurred at much lower temperatures in conventional solid/liquid extraction $\left(105^{\circ} \mathrm{C}\right)$ (Almela, Sánchez-Muñoz, Fernández-López, Roca, \& Rabe, 2006) In the present study, decreases in rosmarinic acid levels at temperatures higher than $150^{\circ} \mathrm{C}$, were accompanied by increases in the caffeic acid content of the extracts with the highest level being reached at $200{ }^{\circ} \mathrm{C}$ (Fig. 3 and Table 3). Since rosmarinic acid is an ester of caffeic acid and 3,4-dihydroxyphenyl lactic acid, caffeic acid might be one of the degradation products. Since the antioxidant activity of pure caffeic acid (423.72 $\mathrm{g}$ Trolox/100 $\mathrm{g} \mathrm{DW}$ ) is higher than that of rosmarinic acid $(406.30 \mathrm{~g}$ Trolox/100 g DW) as measured by FRAP assay (unpublished result) this could explain the increase of antioxidant capacity at temperatures higher than $150{ }^{\circ} \mathrm{C}$. Moreover, the quantity of gallic acid which is a powerful antioxidant (346.21 g Trolox/100 g DW as measured by FRAP assay) in the extracts obtained at $150^{\circ} \mathrm{C}$ or above was significantly higher than that of the extracts obtained at $129^{\circ} \mathrm{C}$ (Table 3). In fact, the extracts of rosemary obtained at $200{ }^{\circ} \mathrm{C}$ contained 3.1 times the gallic acid concentration than the extracts obtained at $129^{\circ} \mathrm{C}$. Quantity of other phenolics such as apigenin-7-O-glucoside, carnosic acid and carnosol of ASE extracts of rosemary, oregano and marjoram obtained at $150{ }^{\circ} \mathrm{C}$ or above did not show significant $(p>0.05)$ change in comparison to optimal ASE extracts. However luteolin-7-O-glucoside showed a significant $(p<0.05)$ decrease in quantity at temperatures of $150{ }^{\circ} \mathrm{C}$ or above in comparison to optimal ASE extracts. The present study observed the formation of Maillard reaction products (melanoidins) at temperatures of $150{ }^{\circ} \mathrm{C}$ or above. The absorbance at $420 \mathrm{~nm}$ of the ASE extracts obtained at $150{ }^{\circ} \mathrm{C}$ or above was significantly higher than that of optimal and solid/liquid extracts (Table 3). The increase in antioxidant activity of the extracts obtained at $150{ }^{\circ} \mathrm{C}$ or above may be related to the production of melanoidins, reported to have antioxidant capacity (Morales \& Babbel, 2002). However, since the Maillard reaction has been reported to produce potentially harmful compounds (Arvidsson, Van Boekel, Skog, \& Jagerstad, 1998) and
3.2. Effect of elevated temperatures $\left(>129^{\circ} \mathrm{C}\right)$ on rosmarinic acid in ASE extracts of Lamiaceae spices
ASE extracts optimised with regard to antioxidant capacity and phenolic content of rosemary, oregano and marjoram had significantly $(p<0.05)$ higher amounts of rosmarinic acid than the conventional solid/liquid extracts (Table 3 ). Since all three spices used showed the best performance at $129^{\circ} \mathrm{C}$, the highest temperature used in the design, the extraction temperatures of $150{ }^{\circ} \mathrm{C}$ $175^{\circ} \mathrm{C}$ and $200^{\circ} \mathrm{C}$ were also used with the optimal methanol concentration for each as described in Section 3.1. When the tem-

Table 3

Content of phenolic compounds and melanoidins in optimal ASE extracts, conventional solid/liquid extracts and the ASE extracts obtained at $150{ }^{\circ} \mathrm{C}, 175{ }^{\circ} \mathrm{C}$ and $200{ }^{\circ} \mathrm{C}$ with optimal methanol concentrations.

\begin{tabular}{|c|c|c|c|c|c|c|c|c|c|}
\hline $\begin{array}{l}\text { Name of } \\
\text { the spice }\end{array}$ & Treatment & $\begin{array}{l}\text { Rosmarinic } \\
\text { acid (mg/g) }\end{array}$ & $\begin{array}{l}\text { Caffeic acid } \\
(\mathrm{mg} / \mathrm{g})\end{array}$ & $\begin{array}{l}\text { Luteolin-7-O- } \\
\text { glucoside }(\mathrm{mg} / \mathrm{g})\end{array}$ & $\begin{array}{l}\text { Apigenin-7-O- } \\
\text { glucoside }(\mathrm{mg} / \mathrm{g})\end{array}$ & $\begin{array}{l}\text { Gallic acid } \\
(\mathrm{mg} / \mathrm{g})\end{array}$ & $\begin{array}{l}\text { Carnosic } \\
\text { acid }(\mathrm{mg} / \mathrm{g})\end{array}$ & $\begin{array}{l}\text { Carnosol } \\
(\mathrm{mg} / \mathrm{g})\end{array}$ & $\begin{array}{l}\text { Melanoidins } \\
\text { (absorbance at } \\
420 \mathrm{~nm} \text { ) }\end{array}$ \\
\hline Rosemary & $\begin{array}{l}\text { Optimal } \\
150^{\circ} \mathrm{C} \\
175^{\circ} \mathrm{C} \\
200{ }^{\circ} \mathrm{C} \\
\text { Solid/ } \\
\text { liquid }\end{array}$ & $\begin{array}{l}15.23 \mathrm{c} \\
14.05 \mathrm{~b} \\
10.29 \mathrm{a} \\
11.10 \mathrm{a} \\
14.50 \mathrm{~b}\end{array}$ & $\begin{array}{l}0.24 b \\
0.22 b \\
0.29 c \\
0.42 d \\
0.12 a\end{array}$ & $\begin{array}{l}0.831 \mathrm{c} \\
0.640 \mathrm{~b} \\
0.559 \mathrm{a} \\
0.520 \mathrm{a} \\
0.703 \mathrm{~b}\end{array}$ & $\begin{array}{l}0.504 b \\
0.476 b \\
0.453 b \\
0.460 b \\
0.320 a\end{array}$ & $\begin{array}{l}0.787 b \\
1.337 c \\
2.456 d \\
2.460 d \\
0.278 a\end{array}$ & $\begin{array}{c}10.986 \mathrm{~b} \\
10.750 \mathrm{~b} \\
10.467 \mathrm{~b} \\
11.070 \mathrm{~b} \\
9.583 \mathrm{a}\end{array}$ & $\begin{array}{l}5.647 b \\
5.462 b \\
5.739 b \\
5.519 b \\
5.660 b\end{array}$ & $\begin{array}{l}0.342 a \\
0.631 b \\
0.685 b \\
0.815 c \\
0.355 a\end{array}$ \\
\hline Marjoram & $\begin{array}{l}\text { Optimal } \\
150^{\circ} \mathrm{C} \\
1755^{\circ} \mathrm{C} \\
200^{\circ} \mathrm{C} \\
\text { Solid/ } \\
\text { liquid }\end{array}$ & $\begin{array}{l}17.50 \mathrm{c} \\
15.69 \mathrm{~b} \\
11.97 \mathrm{a} \\
12.13 \mathrm{a} \\
14.53 \mathrm{~b}\end{array}$ & $\begin{array}{l}0.18 b \\
0.17 b \\
0.18 b \\
0.28 c \\
0.08 a\end{array}$ & $\begin{array}{l}5.674 \mathrm{c} \\
4.158 \mathrm{~b} \\
3.811 \mathrm{a} \\
3.665 \mathrm{a} \\
4.680 \mathrm{~b}\end{array}$ & $\begin{array}{l}0.876 b \\
0.831 b \\
0.765 b \\
0.759 b \\
0.515 a\end{array}$ & $\begin{array}{l}1.152 b \\
1.723 c \\
1.997 c \\
2.016 c \\
0.464 a\end{array}$ & $\begin{array}{l}6.375 b \\
6.245 b \\
6.295 b \\
6.690 b \\
5.333 a\end{array}$ & $\begin{array}{l}5.288 \mathrm{~b} \\
5.273 \mathrm{~b} \\
5.897 \mathrm{~b} \\
5.347 \mathrm{~b} \\
4.480 \mathrm{a}\end{array}$ & $\begin{array}{l}0.475 a \\
0.656 b \\
0.771 c \\
0.836 c \\
0.465 a\end{array}$ \\
\hline Oregano & $\begin{array}{l}\text { Optimal } \\
150^{\circ} \mathrm{C} \\
1755^{\circ} \mathrm{C} \\
200^{\circ} \mathrm{C} \\
\text { Solid/ }\end{array}$ & $\begin{array}{c}10.21 \mathrm{c} \\
9.25 \mathrm{c} \\
3.90 \mathrm{a} \\
3.00 \mathrm{a} \\
5.70 \mathrm{~b}\end{array}$ & $\begin{array}{l}0.36 b \\
0.32 b \\
0.63 c \\
0.64 c \\
0.14 a\end{array}$ & $\begin{array}{l}5.397 \mathrm{c} \\
4.807 \mathrm{~b} \\
2.470 \mathrm{a} \\
2.111 \mathrm{a} \\
2.862 \mathrm{a}\end{array}$ & $\begin{array}{l}2.751 b \\
2.633 b \\
2.570 b \\
2.533 b \\
2.077 a\end{array}$ & $\begin{array}{l}1.040 b \\
1.368 c \\
1.449 c \\
1.491 c \\
0.483 a\end{array}$ & $\begin{array}{l}8.621 b \\
8.415 b \\
8.151 b \\
8.372 b \\
7.533 a\end{array}$ & $\begin{array}{l}6.186 b \\
5.811 b \\
5.871 b \\
5.691 b \\
5.581 a\end{array}$ & $\begin{array}{l}0.453 a \\
0.593 b \\
0.684 c \\
0.735 c \\
0.445 a\end{array}$ \\
\hline
\end{tabular}



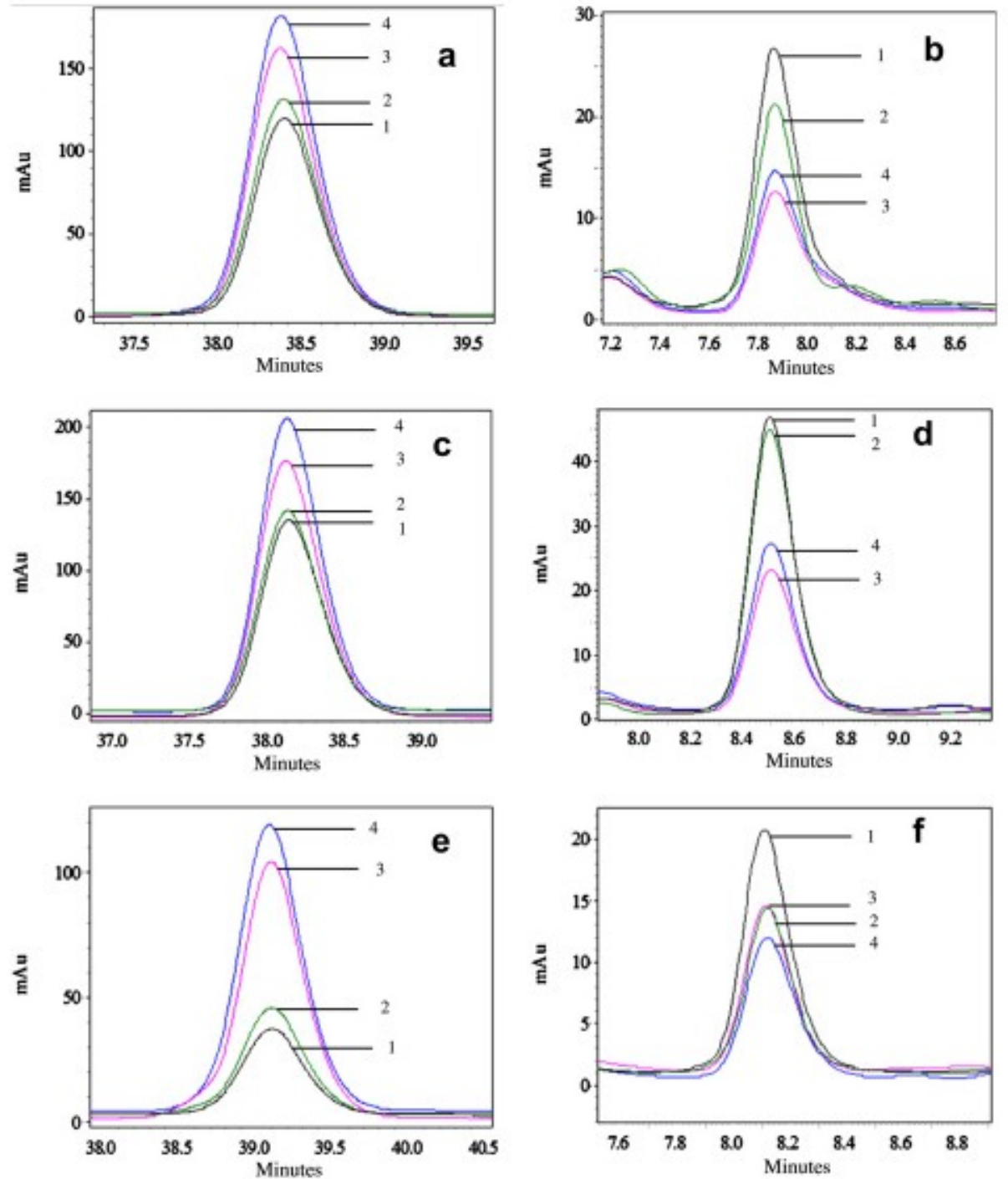

Fig. 3. HPLC chromatograms of rosmarinic and caffeic acid in optimal ASE extracts (line 4) in comparison to the ASE extracts obtained at $150{ }^{\circ} \mathrm{C}$ (line 3 ), $1755^{\circ} \mathrm{C}$ (line 2 ), $200{ }^{\circ} \mathrm{C}$ (line 1) with optimal methanol concentrations in rosemary (a and b, 'a' for rosmarinic acid and ' $b$ ' for caffeic acid), marjoram (c and d, 'c' for rosmarinic acid and ' $\mathrm{d}$ ' for caffeic acid) and oregano (e and f, 'e' 'for rosmarinic acid and ' $f$ ' for caffeic acid).

changed the natural phenolic profile of the extracts, extractions carried out at temperatures in the range of $150-200^{\circ} \mathrm{C}$ are not recommended. Therefore, ASE at $129^{\circ} \mathrm{C}$ with respective methanol concentration was determined to be the optimum for extracting antioxidant compounds from the studied spices.

\section{Acknowledgements}

This work was supported by the Irish Department of Agriculture Fisheries and Food funded Food Institutional Research Measure and ABBEST scholarship programme of Dublin Institute of Technology, Dublin, Ireland.

\section{References}

Akowuah, G. A., Ismail, Z., Norhayati, I., \& Sadikun, A. (2005). The effects of different extraction solvents of varying polarities on polyphenols of Orthosiphon stamineus and evaluation of the

Almela, L., Sánchez-Muñoz, B., Fernández-López, J. A., Roca, M. J., \& Rabe, V. (2006)

Liquid chromatograpic-mass spectrometric analysis of phenolics and free

radical scavenging activity of rosemary extract from different raw material.

Journal of Chromatography A, 1120(1-2), 221-229.
Arvidsson, P., Van Boekel, M. A. J. S., Skog, K., \& Jagerstad, M. (1998). Formation of mutagenic Maillard reaction products. In J. O'Brien, H. E. Nursten, M. J. C. Crabbe, \& J. M. Ames (Eds.). The Maillard reaction in foods and medicine (pp. 219-224). Cambridge, UK: Royal Society of Chemistry.

Babovic, N., Djilas, S., Jadranin, M., Vajs, V., Ivanovic, J., Petrovic, S., et al. (2010).

Supercritical carbon dioxide extraction of antioxidant fractions from selected Supercritical carbon dioxide extraction of antioxidant fractions from selected Emerging Technologies, 11(1), 98-107.

Emerging Technologies, 11(1), 98-107. conditions. Journal of the Royal Statistical Society, 13(1), 1-45.

Bruneton, J. (1999). Pharmacognosy, phytochemistry, medicinal plants. Paris: Technique \& Documentation.

Denery, J. D., Dragull, K., Tang, C. S., \& Li, Q. X. (2004). Pressurized fluid extraction of carotenoids from Haematococcus pluvialis and Dunaliella salina and kavalactones from Piper methysticum. Analytica Chimica Acta, 501, 175-181.

Dhandhukia, P. C., \& Thakkar, V. R. (2008). Response surface methodology to optimise the nutritional parameters for enhanced production of jasmonic acid by Lasiodiplodia theobromae. Journal of Applied Microbiology, 105(3), 636-643.

Elgayyar, M., Draughon, F. A., Golden, D. A., \& Mount, J. R. (2001). Antimicrobial activity of essentials oils from plants against selected pathogenic and saprophytic microorganisms. Journal of Food Protection, 64, 1019.

Ghodke, S. K., Ananthanarayan, L., \& Rodrigues, L. (2009). Use of response surface methodology to investigate the effects of milling conditions on damaged starch, dough stickiness and chapatti quality. Food Chemistry, 112(4), 1010-1015.

Herrero, M., Arráez-Román, D., Segura, A., Kenndler, E., Gius, B., Raggi, M. A., et al. (2005).Pressurizedliquidextraction-capillaryelectrophoresis-mass spectrometry for the analysis of polar antioxidants in rosemary extracts. Journal of Chromatography A, 1084(1-2), 54-62. 
Hirasa, K., \& Takemasa, M. (1998). Spice science and technology. New York: Dekker Inc..

Hossain, M. B., Brunton, N. P., Barry-Ryan, C., Martin-Diana, A. B., \& Wilkinson, M. (2008). Antioxidant activity of spice extracts and phenolics in comparison to synthetic antioxidants. Rasayan Journal of Chemistry, 1(4) 751-756.

Huang, W., Li, Z., Niu, H., Li, D., \& Zhang, J. (2008). Optimization of operating parameters for supercritical carbon dioxide extraction of lycopene by respons surface methodology. Journal of Food Engineering, 89(3), 298-302.

Ibarz, A., Pagán, J., Panadés, R., \& Garza, S. (2005). Photochemical destruction of color compounds in fruit juices. Journal of Food Engineering, 69, 155-160.

Juntachote, T., Berghofer, E., Siebenhandl, S., \& Bauer, F. (2006). The antioxidative properties of holy basil and galangal in cooked ground pork. Meat Science, 72 , $446-456$.

Lampe, J. W. (2003). Spicing up a vegetarian diet: Chemopreventive effects of phytochemicals. American Journal of Clinical Nutrition, 78(3), 579S-583S.

Lee, W. C., Yusof, S., Hamid, N. S. A., \& Baharin, B. S. (2006). Optimizing conditions for hot water extraction of banana juice using response surface methodology (RSM). Journal of Food Engineering, 75(4), 473-479.

Morales, F. J., \& Babbel M. B. (2002). Antiradical efficiency of Maillard reaction mixtures in a hydrophilic media. Journal of Agricultural and Food Chemistry, 50 2788-2792.

Okuda, T., Yamashita, N., Tanaka, H., Matsukawa, H., \& Tanabe, K. (2009) Development of extraction method of pharmaceuticals and their occurrences found in Japanese wastewater treatment plants. Environment International, 35(5), 815-820

Peng, Y., Yuan, J., Liu, F., \& Ye, J. (2005). Determination of active components in rosemary by capillary electrophoresis with electrochemical detection. Journal of Pharmaceutical and Biomedical Analysis, 39, 431-437.

Santoyo, S., Rodríguez-Meizoso, I., Cifuentes, A., Jaime, L., García-Blairsy Reina, G. Señorans, F. J., et al. (2009). Green processes based on the extraction with pressurized fluids to obtain potent antimicrobials from Haematococcus pluvialis microalgae. LWT - Food Science and Technology, 42(7), 1213-1218.

Shan, B., Cai, Y. Z., Sun, M., \& Corke, H. (2005). Antioxidant capacity of 26 spice extracts and characterization of their phenolic constituents. Journal of Agricultural and Food Chemistry, 53, 7749-7759.
Simándi, B., Oszagyán, M., Lemberkovics, É., Kéry, Á., Kaszács, J., Thyrion, F., et al. (1998). Supercritical carbon dioxide extraction and fractionation of oregano oleoresin. Food Research International, 31(10), 723-728.

Singelton, V. L., Orthofer, R., \& Lamuela-Raventos, R. R. (1999). Analysis of total phenols and other oxidation substrates and oxidants by means of FolinCiocalteu reagent. Methods in Enzymology, 299, 152-178.

Siriwong, W., Thirakhupt, K., Sitticharoenchai, D., Rohitrattana, J., Thongkongowm, P., Borjan, M., et al. (2009). DDT and derivatives in indicator species of the P., Borjan, Indicators, 9(5), 878-882.
Indic

Srinivasan, K. (2005). Spices as influencers of body metabolism: an overview of three decades of research. Food Research International, 38(1), 77-86.

Stratil, P., Klejdus, B., \& Kuban, V. (2006). Determination of total content of phenolic compounds and their antioxidant activity in vegetables - Evaluation of spectrophotometric methods. Journal of Agricultural and Food Chemistry, 54, spectroph

Suhaj, M. (2006). Spice antioxidants isolation and their antiradical activity: A review. Journal of Food Composition and Analysis, 19(6-7), 531-537.

Tan, C. H., Ghazali, H. M., Kuntom, A., Tan, C. P., \& Ariffin, A. A. (2009). Extraction and physicochemical properties of low free fatty acid crude palm oil. Food Chemistry, $113(2), 645-650$

Tsao, R., \& Yang, R. (2003). Optimization of a new mobile phase to know the complex and real polyphenolic index using high-performance liquid chromatography. Journal of Chromatography A, 1018, 29-40.

Zaibunnisa, A. H., Norashikin, S., Mamot, S., \& Osman, H. (2009). An experimenta design approach for the extraction of volatile compounds from turmeric leaves (Curcuma domestica) using pressurised liquid extraction (PLE). LWT - Food Science and Technology, 42(1), 233-238.

Zgórka, G. (2009). Pressurized liquid extraction versus other extraction techniques in micropreparative isolation of pharmacologically active isoflavones from Trifolium L. Species. Talanta, 79(1), 46-53.

Zheng, W., \& Wang, S. Y. (2001). Antioxidant activity and phenolic compounds in selected herbs. Journal of Agricultural and Food Chemistry, 49, 5165-5170.

Zizovic, I., Stamenic, M., Orlovic, A., \& Skala, D. (2005). Supercritical carbon dioxide essential oil extraction of Lamiaceae family species: Mathematical modelling on the micro-scale and process optimization. Chemical Engineering Science, 60(23), 6747-6756. 